\title{
Hospital admissions and exercise capacity decline in patients with COPD
}

\author{
Maria A. Ramon, Elena Gimeno-Santos, Jaume Ferrer, Eva Balcells, \\ Esther Rodríguez, Jordi de Batlle, Federico P. Gómez, Jaume Sauleda, \\ Antoni Ferrer, Joan A. Barberà, Alvar Agustí, Joaquim Gea, \\ Robert Rodriguez-Roisin, Josep M. Antó, Judith Garcia-Aymerich and \\ the PAC-COPD Study Group
}

Affiliations: For the authors' affiliations, and a list of the PAC-COPD Study Group members and their affiliations, see the Acknowledgements.

Correspondence: J. Garcia-Aymerich, CREAL, Doctor Aiguader 88, 08003 Barcelona, Spain. E-mail: jgarciadcreal.cat

ABSTRACT Exercise capacity declines with time and is an important determinant of health status and prognosis in patients with chronic obstructive pulmonary disease (COPD). We hypothesised that hospital admissions are associated with exercise capacity decline in these patients.

Clinical and functional variables were collected for 342 clinically stable COPD patients. The 6-min walk distance (6MWD) was determined at baseline and after a mean \pm SD of $1.7 \pm 0.3$ years. Information on hospitalisations during follow-up was obtained from centralised administrative databases. Linear regression was used to model changes in exercise capacity.

Patients were mostly male $(92 \%)$, with mean \pm SD age $67.9 \pm 8.6$ years, post-bronchodilator forced expiratory volume in $1 \mathrm{~s} 54 \pm 17 \%$ predicted and baseline $6 \mathrm{MWD} 433 \pm 93 \mathrm{~m}$. During follow-up, 6MWD decreased by $21.9 \pm 51.0 \mathrm{~m} \cdot$ year $^{-1}$ and $153(45 \%)$ patients were hospitalised at least once. Among patients admitted only for COPD-related causes ( $50 \%$ of those ever admitted), the proportion presenting a clinically significant loss of 6MWD was higher than in patients admitted for only nonrespiratory conditions $(53 \%$ versus $29 \%, \mathrm{p}=0.040)$. After adjusting for confounders, annual $6 \mathrm{MWD}$ decline was greater $\left(26 \mathrm{~m} \cdot \mathrm{year}^{-1}\right.$, 95\% CI $13-38 \mathrm{~m} \cdot$ year $\left.^{-1} ; \mathrm{p}<0.001\right)$ in patients with more than one all-cause hospitalisation per year, as compared with those with no hospitalisations.

Hospitalisations are related to a greater decline in exercise capacity in COPD.

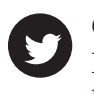

@ERSpublications

Hospitalisations are associated with higher decline in exercise capacity in COPD patients http://ow.ly/rB8cc

This article has supplementary material available from www.erj.ersjournals.com

Received: May 232013 | Accepted after revision: Nov 282013 | First published online: Jan 32014

Support statement: The PAC-COPD Study is funded by grants from: Fondo de Investigación Sanitaria (FIS PI020541), Ministry of Health, Spain; Agència d'Avaluació de Tecnologia i Recerca Mèdiques (AATRM 035/20/02), Catalonia Government; Spanish Society of Pneumology and Thoracic Surgery (SEPAR 2002/137); Catalan Foundation of Pneumology (FUCAP 2003 Beca Marià Ravà); Red RESPIRA (RTIC C03/11); Red RCESP (RTIC C03/09), Fondo de Investigación Sanitaria (PI052486); Fondo de Investigación Sanitaria (PI052302); Fundació La Marató de TV3 (number 041110); DURSI (2005SGR00392); and unrestricted educational grants from Novartis Farmacèutica, Spain, and AstraZeneca Farmacéutica, Spain. CIBERESP and CIBERES are funded by the Instituto de Salud Carlos III, Ministry of Health, Spain. There was no involvement of the funding sources in study design; in the collection, analysis and interpretation of data; in the writing of the report; or in the decision to submit the article for publication. The researchers are independent from the funders.

Conflict of interest: Disclosures can be found alongside the online version of this article at www.erj.ersjournals.com

Copyright @ERS 2014 


\section{Introduction}

Chronic obstructive pulmonary disease (COPD) is characterised by poorly reversible airflow limitation [1] and reduced exercise capacity [2]. This often decreases the ability to participate in activities of daily living and the quality of life of COPD patients [3]. Furthermore, exercise limitation in COPD relates to higher healthcare resource utilisation and is a predictor of mortality $[4,5]$. Accordingly, the assessment of exercise capacity is currently considered an important outcome to determine prognosis and response to therapeutic interventions in COPD $[6,7]$.

Previous studies have clearly shown that exercise capacity declines over time in patients with COPD $[8,9]$. This decline appears higher than that observed in other functional variables such as forced expiratory volume in $1 \mathrm{~s}$ (FEV1) [9], suggesting that repeated measures of exercise capacity might be a more sensitive marker of changes in clinical status in these patients than measurements of pulmonary function. However, there is a limited understanding of the factors that affect exercise capacity decline over time in COPD. Identifying such factors will be helpful to design and/or implement interventions that reduce exercise capacity deterioration and, consequently, its deleterious impact.

Patients with COPD often require hospitalisation during the course of their disease. It is well established that these episodes of hospitalisation negatively affect their functional status and health outcomes [10, 11]. In particular, hospitalisations are known to be associated with a significant decrease in peripheral muscle force [12], probably in relation to prolonged bed rest and physical inactivity [13, 14]. In fact, early introduction of a rehabilitation programme following a hospitalisation is highly effective in improving exercise capacity and reducing future hospital admissions in these patients [15]. Conceivably, hospitalisations during the course of the disease can therefore be a major factor of the decline in exercise capacity that occurs in COPD. Accordingly, we hypothesised that, in patients with COPD: 1) hospitalisations (irrespective of their cause) are associated with a faster decline in exercise capacity over time, and that a higher rate of hospitalisation and/or a longer cumulative hospital stay are associated with a greater loss of exercise capacity; and 2) the relationship between hospitalisations due to COPD exacerbation and exercise decline is greater than that observed in other causes of hospitalisations. Thus, the present study was designed to investigate the association between hospitalisations and exercise capacity decline in patients with COPD.

\section{Methods}

Detailed information about the methods has been previously reported [16, 17] and is summarised in the online supplementary material.

\section{Study design and participants}

The present longitudinal study is based on the population of the Phenotype and Course of COPD (PACCOPD) study described elsewhere [17]. Briefly, COPD patients were recruited during their first hospitalisation due to COPD exacerbation, in nine teaching hospitals in Spain [16]. Patients were evaluated 3 months after discharge, when clinically stable (baseline). The diagnosis of COPD was established according to the American Thoracic Society/European Respiratory Society guidelines [18]. Patients were invited to participate in a second visit for follow-up assessment 18-24 months later. Of the 342 patients enrolled in PAC-COPD, 226 (66\%) had exercise capacity measures in the two visits (online supplementary fig. E1, and tables E1 and E2). The study was approved by the ethics committees of participating hospitals and all patients gave their informed consent.

\section{Measurements}

As reported elsewhere [16], sociodemographic data, smoking history, dietary habits, dyspnoea, healthrelated quality of life, anxiety and depression, comorbidities, physical activity, FEV1/forced vital capacity ratio before and after bronchodilation, residual volume (RV), total lung capacity (TLC), diffusing capacity of the lung for carbon monoxide (DLCO), arterial oxygen tension $\left(\mathrm{PaO}_{2}\right)$, body mass index $(\mathrm{BMI})$, fat-free mass index, handgrip strength, maximum inspiratory (MIP) and expiratory pressures (MEP), and serum levels of tumour necrosis factor- $\alpha$ were determined at baseline following standardised methodology. Participation in pulmonary rehabilitation programmes during follow-up was also recorded.

Exercise capacity was assessed using the 6-min walk distance (6MWD) following published recommendations [6]. The annual rate of change in exercise capacity was calculated as the difference between the follow-up and baseline 6MWD divided by follow-up time in each patient, and patients were classified into two groups according to the updated minimal clinically important difference (MCID) of $\geqslant 35$ or $<35 \mathrm{~m} \cdot$ year $^{-1}[19,20]$. 
Information on dates and causes of hospitalisations during follow-up was obtained from a national administrative database. Hospitalisation rate was defined as the number of hospitalisations (all causes) during follow-up divided by follow-up time in each subject. Causes of admission were classified according to the International Classification of Diseases, 9th revision (see the online supplementary material for more details). To study the specific role of COPD admissions, patients were classified in two main groups: 1) patients with "only COPD" hospitalisations, due exclusively to a COPD exacerbation; and 2) patients with "nonrespiratory" hospitalisations, due to causes unrelated to respiratory conditions. A third group of patients combining respiratory and nonrespiratory admissions was labelled as "mixed cause" hospitalisations, and used only for descriptive purposes. In patients requiring hospitalisation during follow-up, we computed the cumulative hospital stay during follow-up, and the time elapsed between the last hospital discharge and the second visit.

\section{Statistical analysis}

Statistical analysis and sample size power estimation are detailed in the online supplementary material. To account for selective attrition and missing values, we used multiple imputation (20 times) through chained equations, replacing missing values by imputations drawn from the predictive distribution of each variable [21]. Table E3 shows the descriptive characteristics of both the real population and the imputed population. Multivariate linear regression models were used to assess the association between hospitalisations and exercise capacity decline, after adjusting for baseline 6MWD. Potential confounders were tested and included in the final models if 1) they related to both the exposure and the outcome, 2) they modified $(>10 \%$ change in regression coefficient) the estimates of the remaining variables, or 3$)$ there was consistent evidence in the literature of their association with exercise capacity. Further stratification analyses according to sex, age, BMI, daily physical activity, FEV1 and muscle force (handgrip, MIP and MEP) were conducted in order to study possible interactions. Sensitivity analysis was conducted 1) using the cut-off point of $26 \mathrm{~m} \cdot$ year $^{-1}$ as the clinically significant threshold of exercise capacity decline [22], 2) excluding subjects who participated in any pulmonary rehabilitation programme during follow-up and 3) using a complete case analysis. Analysis was conducted using Stata 9.1 (StataCorp, College Station, TX, USA).

\section{Results}

Table 1 presents the main clinical and functional characteristics of the 342 patients studied at baseline. Most participants $(92 \%)$ were males. Mean \pm SD age was $67.9 \pm 8.6$ years. About a third of patients were current smokers. Comorbidities were frequent and about half of patients reported significant dyspnoea. On average, airflow limitation was moderate, ranging from mild to very severe. Most patients had gas trapping and impaired DLCO with mild arterial hypoxaemia.

Patients were followed for a mean of $1.7 \pm 0.3$ years. The mean $6 \mathrm{MWD}$ was $433 \pm 93 \mathrm{~m}$ at baseline and $396 \pm 99 \mathrm{~m}$ at the second evaluation. Mean change in $6 \mathrm{MWD}$ was $-21.9 \pm 51.0 \mathrm{~m} \cdot$ year $^{-1}$ (table 1 and fig. E2) and $\sim 20 \%$ of patients experienced an increase in exercise capacity during follow-up. A 6MWD decline $\geqslant 35 \mathrm{~m} \cdot$ year $^{-1}$ (MCID) occurred in 113 (33\%) subjects. According to spirometric severity, there was a trend in the association between baseline 6MWD and COPD severity grades $(466 \pm 122,443 \pm 94,431 \pm 96$ and $358 \pm 116 \mathrm{~m}$ in patients with mild, moderate, severe and very severe COPD, respectively; $\mathrm{p}<0.001$ for trend). However, there were no differences in $6 \mathrm{MWD}$ changes across these COPD groups $(-16 \pm 70$, $-19 \pm 51,-27 \pm 55$ and $-19 \pm 75 \mathrm{~m} \cdot$ year $^{-1}$, respectively; $\mathrm{p}=0.350$ for trend). During follow-up, $153(45 \%)$ patients were hospitalised (all causes). The most frequent cause of admission was a COPD exacerbation (52\%). Tables 2 and 3 present detailed information on the characteristics of hospitalisations during follow-up. A very small proportion (5\%) of patients was enrolled in pulmonary rehabilitation programmes during follow-up.

Hospitalisations during follow-up, as well as the frequency of all-cause hospitalisations, were associated with a significantly greater decline in 6MWD in unadjusted analyses (table 4 and fig. 1). The rate of 6MWD decline was greater in patients with only-COPD admissions than in patients admitted for nonrespiratory causes, but this difference was not statistically significant (table 4 and fig. 2). A higher proportion of patients with only-COPD admissions experienced a clinically significant loss in 6MWD compared with patients with nonrespiratory admission $(53 \%$ versus $29 \%, \mathrm{p}=0.040)$. There was no association between $6 \mathrm{MWD}$ decline and cumulative hospital length of stay or time elapsed from last hospital discharge to the second evaluation (table 4).

Table 5 shows that, after adjusting for age, sex, dyspnoea, BMI, RV/TLC, $\mathrm{PaO}_{2}$ and baseline 6MWD, suffering one or more than one (all-cause) hospitalisation per year was associated with an increase in the mean annual decline of 6MWD by 7.4 and $26.1 \mathrm{~m}$, respectively, as compared with patients who were not hospitalised during follow-up ( $\mathrm{p}=0.211$ and $\mathrm{p}<0.001$, respectively). This decline was similar across causes of admissions. 
All patients

Patients $\mathbf{n}$

Anthropometric and clinical data

Males

314 (92)

Age years

$67.9+8.6$

Current smokers

120 (35)

YPAS physical activity index

$34(20-53)$

SGRQ total score ${ }^{+}$

$33(23-48)$

Charlson index $\geqslant 2$

194 (57)

Body mass index $\mathrm{kg} \cdot \mathrm{m}^{-2}$

$28.2 \pm 4.7$

Fat-free mass index $\mathrm{kg} \cdot \mathrm{m}^{-2}$

$19.7 \pm 3.1$

Significant dyspnoea

$158(46)$

Lung function

Post-bronchodilator FEV1 \% pred

$54 \pm 17$

COPD severity

Stage $\mathrm{I}^{f}$

Stage $\|^{\# \#}$

$19(6)$

Stage $111^{\circ \cdot}$

$164(48)$

Stage $\mathrm{IV}^{++}$

$132(38)$

27 (8)

RV/TLC \%

$55.9 \pm 10.5$

DLco \% pred

$64.4+22.7$

$\mathrm{PaO}_{2} \mathrm{mmHg}$

$74.4 \pm 10.9$

Exercise capacity and muscle force

6MWD at baseline $m$

$433 \pm 93$

6MWD at follow-up visit $m$

$396+99$

Change in 6MWD $\mathrm{m} \cdot$ year $^{-1}$

Patients with clinically significant change in $6 M W D^{\S \S}$

$-21.9+51.0$

Handgrip muscle force $\mathrm{kg}$

$113(33)$

MIP \% pred

$30.5+8.5$

Pulmonary rehabilitation during follow-up ${ }^{f f}$

$68 \pm 27$

13 (5)

Follow-up time years

$1.70 \pm 0.34$

Data are presented as $\mathrm{n}(\%)$, mean \pm SD or median (interquartile range), unless otherwise stated. YPAS: Yale Physical Activity Survey; SGRQ: St George's Respiratory Questionnaire; FEV1: forced expiratory volume in $1 \mathrm{~s}$; COPD: chronic obstructive pulmonary disease; RV: residual volume; TLC: total lung capacity; DLCo: diffusing capacity of the lung for carbon monoxide; $\mathrm{PaO}_{2}$ : arterial oxygen tension; 6MWD: 6-min walk distance; MIP: maximum inspiratory pressure. ${ }^{\#}$ : descriptive analyses were conducted using imputed datasets where there were missing data; online supplementary table E3 shows the descriptive characteristics of both complete cases and imputed samples. ": scored from 0 to $137 .{ }^{+}$: scored from 0 to $100 .^{\S}$ : modified Medical Research Council score $\geqslant 2 .{ }^{f}$ : mild (FEV1 $\geqslant 80 \%$ pred). ${ }^{\# \#}$ : moderate (FEV $1 \geqslant 50 \%$ or $<80 \%$ pred). " " severe (FEV1 $\geqslant 30 \%$ or $<50 \%$ pred). ${ }^{++}$: very severe (FEV1 $<30 \%$ pred). ${ }^{\S \S}: \geqslant 35 m \cdot$ year ${ }^{-1} \cdot{ }^{f f}: n=251$.

TABLE 2 Hospital admissions during 1.7-year follow-up of 342 chronic obstructive pulmonary disease patients

Any" admission during follow-up

$153(45)$

Number of admissions" ${ }^{\#}$ per year during follow-up

0

$189(55)$

$>0$ and $\leqslant 1$

$73(21)$

$>1$

$80(24)$

Distribution of patients according to admissions and their causes ${ }^{\pi}$

No admission

189 (55)

Only COPD

$89(55)$

Nonrespiratory

Mixed causes

$43(13)$

$33(10)$

Cumulative hospital stay ${ }^{+}$days

$13(5-28)$

Time from last discharge to second evaluation ${ }^{+}$days

Data are presented as $\mathrm{n}(\%)$ or median (interquartile range). ${ }^{*}$ : all causes; ${ }^{\circ}$ : see main text for definitions; ${ }^{+}: \mathrm{n}=153$. 
TABLE 3 Causes of 376 hospital admissions during 1.7-year follow-up of 153 chronic obstructive pulmonary disease (COPD) patients

ICD9 code

\begin{tabular}{|c|c|c|c|}
\hline & & \\
\hline & & $\begin{array}{l}\text { Cause of } \\
\text { admission" }\end{array}$ & $\begin{array}{c}\text { Length of hospital } \\
\text { stay days }\end{array}$ \\
\hline All-cause admissions & & $376(100)$ & $6(3-10)$ \\
\hline COPD & $490-496$ & $196(52)$ & $6(3-9)$ \\
\hline Other respiratory non-COPD & 460-519 except 490-496 & $46(12)$ & $7(4-10)$ \\
\hline Cardiovascular & $390-459$ & $38(10)$ & $7(3-14)$ \\
\hline Cancer & $140-239$ & $28(7)$ & $6(3-10)$ \\
\hline Digestive & $520-579$ & $21(6)$ & $4(3-8)$ \\
\hline Genitourinary & $580-629$ & $17(5)$ & $6(5-9)$ \\
\hline Aftercare & V50-V69 & $7(2)$ & $4(2-8)$ \\
\hline Musculoskeletal & $710-739$ & $7(2)$ & $8(7-8)$ \\
\hline Infectious and parasitic diseases & $001-139$ & $4(1)$ & $36(7.5-80)$ \\
\hline Injury and poisoning & $800-999$ & $3(0.8)$ & $8(6-17)$ \\
\hline Nervous system and sense organs & $320-389$ & $3(0.8)$ & $17(2-25)$ \\
\hline Diseases of the skin & $680-709$ & $3(0.8)$ & $5(2-13)$ \\
\hline Diseases of the blood & $280-289$ & $1(0.3)$ & $12^{\bullet}$ \\
\hline Endocrine disorders & $240-279$ & $1(0.3)$ & $15^{\circ}$ \\
\hline Mental disorders & $290-319$ & $1(0.3)$ & 2 \\
\hline
\end{tabular}

Data are presented as $\mathrm{n}(\%)$ or median (interquartile range). There were no admission causes other than those included here. ICD9: International Classification of Diseases, 9th revision. ${ }^{\#}$ : ordered by frequency; ${ }^{\natural}: \mathrm{n}=1$.

TABLE 4 Unadjusted relationship between hospital admissions and annual change in 6-min walk distance ${ }^{\#}$ (6MWD) during 1.7-year follow-up of 342 chronic obstructive pulmonary disease (COPD) patients

Change in 6MWD p-value

$\mathrm{m} \cdot$ year $^{-1}$

\begin{tabular}{|c|c|c|c|c|c|}
\hline \multicolumn{6}{|c|}{ Any ${ }^{f}$ admission during follow-up } \\
\hline No & $-13.8 \pm 35.9$ & \multirow[t]{2}{*}{0.003} & $142(75)$ & $47(25)$ & \multirow[t]{2}{*}{0.002} \\
\hline Yes & $-32.5 \pm 51.7$ & & 87 (57) & $66(43)$ & \\
\hline \multicolumn{6}{|c|}{ Number of admissions ${ }^{f}$ per year during follow-up } \\
\hline$>0$ and $\leqslant 1$ & $-26.1 \pm 51.9$ & \multirow{2}{*}{$0.002^{\pi}$} & $46(63)$ & 27 (37) & \multirow{2}{*}{$0.001^{\oplus}$} \\
\hline$>1$ & $-38.4 \pm 70.9$ & & $41(52)$ & $39(48)$ & \\
\hline \multicolumn{6}{|c|}{ Cause of admission ${ }^{\# \#}$} \\
\hline Mixed causes & $-28.2 \pm 48.7$ & $0.236^{++}$ & $20(61)$ & $13(39)$ & $0.040^{++}$ \\
\hline \multicolumn{6}{|c|}{ Quartiles of cumulative hospital stay ${ }^{\# \#}$ days } \\
\hline 1 to $\leqslant 5$ & $-29.8 \pm 37.6$ & \multirow[t]{4}{*}{$0.610^{\top}$} & $25(61)$ & 16 (39) & \multirow[t]{4}{*}{$0.682^{\circ}$} \\
\hline$>5$ to $\leqslant 13$ & $-33.1 \pm 48.7$ & & $20(51)$ & $18(49)$ & \\
\hline$>13$ to $\leqslant 28$ & $-29.1 \pm 49.8$ & & $23(64)$ & $13(36)$ & \\
\hline$>28$ & $-38.1 \pm 51.5$ & & $19(50)$ & $19(50)$ & \\
\hline$>206$ to $\leqslant 363$ & $-36.1 \pm 49.4$ & \multirow{2}{*}{$0.445^{\circ \oplus}$} & $20(53)$ & $18(47)$ & \multirow{2}{*}{$0.735^{\bullet}$} \\
\hline$>363$ & $-25.8 \pm 46.4$ & & $23(60)$ & $15(40)$ & \\
\hline
\end{tabular}

Data are presented as mean \pm SD or $\mathrm{n}(\%)$, unless otherwise stated. ${ }^{\#}$ : presented both as a continuous variable and according to clinically significant change, for a better understanding of the effect of hospitalisations; each combination of hospitalisation variables and change in the $6 \mathrm{MWD}$ is a single unadjusted model. `: $\geqslant 35$ m·year ${ }^{-1} .{ }^{+}: n=229 .{ }^{\S}: n=113 .{ }^{f}$ : all causes. ${ }^{\# \#}: n=153 . ~ "$ ": $p$-value for trend. ${ }^{++}$: “only COPD" versus "nonrespiratory"; "mixed causes" is only presented for descriptive purposes. 
FIGURE 1 Annual change in 6-min walk distance (6MWD) according to annual rate of hospital admission during 1.7-year follow-up in 342 chronic obstructive pulmonary disease patients. Data are presented as means with $95 \%$ confidence intervals.

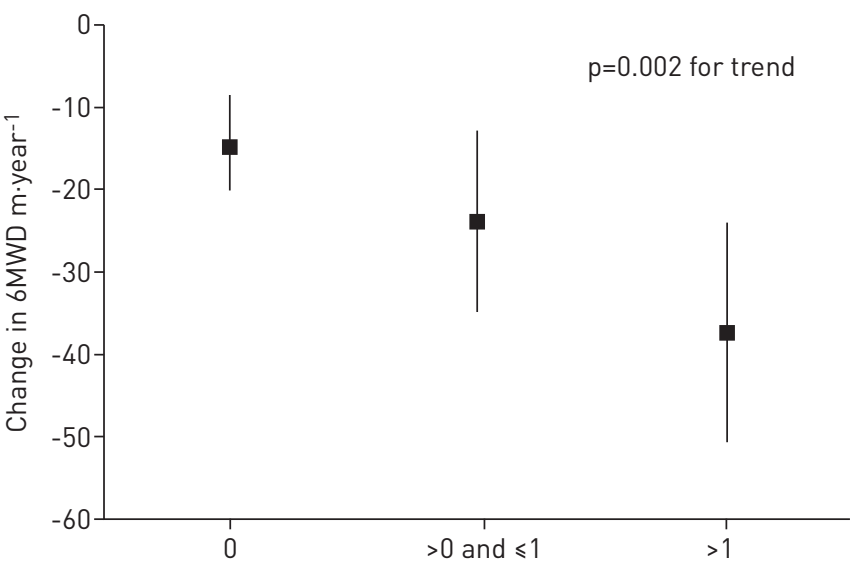

Number of all-cause hospital admissions per year

Stratification according to potential effect modifiers did not show any difference. All sensitivity analyses yielded very similar results (table E4 compares the main results using both complete case and imputed datasets).

\section{Discussion}

There are three main novel findings in this study. First, 6MWD decline was greater in those COPD patients who were hospitalised (all causes) during follow-up; second, this association is significantly greater in patients with frequent hospitalisations (all causes); and third, the decline does not seem to be related to the cause of admission.

\section{Previous studies}

It is well established that hospital admissions contribute to poor health outcomes in COPD patients [1, 10, 11]. So far, however, the relationship between exacerbations and hospitalisations and the decline in exercise capacity has been rarely studied. A previous smaller study (56 patients) investigated the association between the frequency and duration of COPD exacerbations and changes in the BODE (BMI, airflow obstruction, dyspnoea, exercise capacity) index, which includes the 6MWD, and reported that their duration had a greater impact on 6MWD than their frequency [23]. Unfortunately, these results cannot be compared with ours because that study did not distinguish between exacerbations requiring hospital care and those managed in the community; besides, no information was collected about admissions due to comorbidities.

\section{Interpretation of findings}

The results of this study identify a clear and statistically significant association of all-cause hospitalisation with exercise capacity decline in COPD. Several potential mechanisms can be conceived to explain this relationship. For instance, it is well known that bed rest and physical inactivity impair skeletal muscle mass and function $[13,14]$. Likewise, all-cause hospitalisations can be markers of poor general health and, hence,

FIGURE 2 Annual change in 6-min walk distance (6MWD) according to cause of hospital admission during 1.7-year follow-up in 342 chronic obstructive pulmonary disease (COPD) patients. Data are presented as means with $95 \%$ confidence intervals.

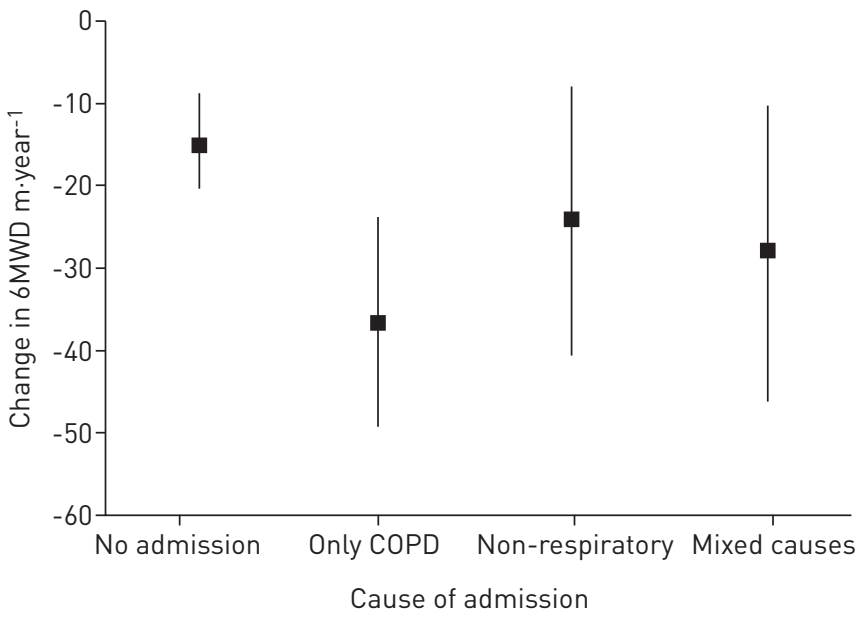


TABLE 5 Adjusted association between hospitalisation rate and annual change in 6-min walk distance (6MWD) during 1.7-year follow-up in 342 chronic obstructive pulmonary disease (COPD) patients ${ }^{\#}$ in all patients and according to cause of admission

\begin{tabular}{|c|c|c|c|c|c|c|}
\hline & \multicolumn{2}{|l|}{ All patients } & \multicolumn{2}{|c|}{$\begin{array}{c}\text { Patients with only-COPD } \\
\text { admissions }^{\pi} \text { versus no } \\
\text { admissions }^{+}\end{array}$} & \multicolumn{2}{|c|}{$\begin{array}{c}\text { Patients with nonrespiratory } \\
\text { admissions }{ }^{5} \text { versus no } \\
\text { admissions }^{+}\end{array}$} \\
\hline Constant ${ }^{\# \#}$ & $-7.3(-15.8-1.2)$ & 0.088 & $-7.7(-15.8-0.6)$ & 0.068 & $-8.5(-16.7--0.3)$ & 0.043 \\
\hline \multicolumn{7}{|l|}{$\begin{array}{l}\text { Number of hospital } \\
\text { admissions per year } \\
\text { during follow-up }\end{array}$} \\
\hline 0 & Reference & & Reference & & Reference & \\
\hline$>0$ and $\leqslant 1$ & $-7.4(-19.1-4.3)$ & 0.211 & $-13.8(-28.2-2.1)$ & 0.092 & $-1.5(-18.7-15.7)$ & 0.865 \\
\hline$>1$ & $-26.1(-38.6--13.1)$ & $<0.001$ & $-28.0(-45.1--10.7)$ & 0.002 & $-27.3(-48.9--5.6)$ & 0.014 \\
\hline $\begin{array}{l}\text { Significant dyspnoea }{ }^{\text {TाT }} \text { at } \\
\text { baseline }\end{array}$ & $-17.2(-27.8--6.6)$ & 0.002 & $-16.9(-28.3--5.4)$ & 0.004 & $-15.3(-26.4--4.1)$ & 0.008 \\
\hline Age at baseline years & $-0.6(-1.3-0.01)$ & 0.057 & $-0.6(-1.2-0.1)$ & 0.089 & $-0.6(-1.3-0.1)$ & 0.098 \\
\hline Baseline 6MWD m & $-0.2(-0.3--0.1)$ & $<0.001$ & $-0.2(-0.3--0.1)$ & $<0.001$ & $-0.2(-0.3--0.1)$ & $<0.001$ \\
\hline Adjusted $\mathbf{R}^{2}$ & 0.223 & & 0.229 & & 0.193 & \\
\hline \multicolumn{7}{|c|}{ 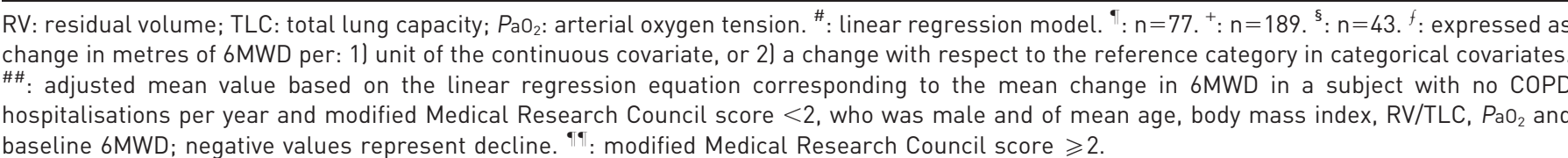 } \\
\hline
\end{tabular}

poor prognosis. Other more specific factors may also operate in particular causes of admissions including: 1) a burst of systemic inflammation, known to occur during exacerbations of COPD [24] or acute cardiovascular diseases [25], that can reduce quadriceps strength and exercise capacity [12]; or 2) the use of systemic corticosteroid therapy $[1,18]$, commonly used in case of COPD admissions, that can cause skeletal muscle dysfunction [26]. The fact that, in this study, neither the total duration of hospital stay nor the time from hospital discharge to the second evaluation were related to the annual 6MWD decline suggest that other specific mechanisms may play a more active and important pathogenic role than simply the passive physical inactivity associated with any hospitalisation event. Certainly, further clinical and experimental research is needed to identify these mechanisms, since this is usually beyond the scope of epidemiological studies.

Two other findings of this study deserve specific discussion. Firstly, the results indicate that dyspnoea is an independent predictor of the decline in exercise capacity in COPD patients. The association of dyspnoea with exercise capacity is well established in COPD [27]. In addition, an enhanced perception of dyspnoea can reduce the practice of physical activity, which subsequently would decrease exercise capacity. Furthermore, previous studies have shown that dyspnoea is a predictor of survival in these patients [28] and that it gets better after improving exercise capacity through pulmonary rehabilitation programmes [29]. To our knowledge, however, no previous study has reported a relationship between dyspnoea and an accelerated annual decline in exercise capacity in COPD. Secondly, and surprisingly, baseline FEV1 and RV/TLC were not related to 6MWD decline in our study. Yet this is in keeping with the results of a previous study of 198 patients with severe COPD followed for 2 years, which showed that the annual decline of 6MWD was independent of FEV1 changes [8].

An estimated $20 \%$ of patients evaluated in our study experienced an increase in exercise capacity during follow-up. This fact has been previously reported for FEV1 [30]. Potential explanations include 1) regression to the mean, 2) a learning effect in patients who underwent repeated exercise capacity tests with their doctors during follow-up, or 3) an improvement of clinical and functional status if the first hospitalisation triggered a more aggressive treatment by doctors or higher awareness in relation to disease in patients and their carers. 


\section{Clinical implications}

The results of this study have clinical implications given that poor exercise performance has been related to a greater risk of hospitalisation and mortality in COPD patients [4, 8]. Pulmonary rehabilitation programmes starting within a few days of hospital admission or immediately after discharge has been shown to produce clinically meaningful improvements in exercise capacity and quadriceps strength in COPD patients [29]. In addition, a recently published meta-analysis of randomised controlled trials concluded that post-exacerbation rehabilitation can reduce hospital re-admissions and mortality in COPD patients [15]. Thus, these data complement and extend the previous observations, and support the need for pulmonary rehabilitation in COPD patients during or immediately after hospitalisation. The high proportion (56\%) of patients with a clinically relevant loss of exercise capacity among those admitted only for COPD-related causes as compared with other conditions makes COPD admission a highly specific target for such interventions. Unfortunately, only a small proportion (5\%) of our hospitalised COPD patients were enrolled in pulmonary rehabilitation programmes, so we were not able to explore the potential effectiveness of such programmes in our study population.

\section{Strengths and limitations}

The large sample size, careful phenotypic characterisation of participants [17], relatively long period of follow-up and novelty of the hypothesis investigated are clear strengths of this study. In addition, missing data could have introduced selection bias in the estimates of our analyses. Therefore, we used multiple imputation to compensate for the underrepresentation of subjects lost to follow-up, which is known to be more accurate than complete case analyses in estimating statistical associations [21]. Among potential limitations, we acknowledge that the PAC-COPD study reflects a population with sex and severity distributions that may not be representative of COPD patients from countries with different social or sanitary organisations. However, such differences are unlikely to affect the results of the association between hospital admissions and exercise capacity decline. Our study was restricted to patients who were hospitalised for COPD and, thus, our findings may be considered to apply only to relatively severe COPD. However, the selection of patients at their first hospital admission due to COPD should be seen as a strength that allows for a more valid study of the factors that affect the prognosis of COPD [31].

PAC-COPD lacks a control arm, but in the current analysis we compared COPD patients who required hospitalisations with those who did not, which makes a control group unnecessary. Likewise, we do not have information on quadriceps strength, which is a strong correlate of exercise capacity in COPD. Instead, we tested hand-grip strength and respiratory muscle force versus exercise capacity changes and no association was observed. Thus, considering that both upper and lower muscle function can be impaired in COPD patients [32], we believe that any residual confounding effect should be very small, if any. In PACCOPD, a practice 6-min walk was not conducted at the follow-up visit. As there was a relatively long time interval between the baseline and second evaluation, the learning effect could have been missed at followup. However, the absence of a practice test was present equally in patients who suffered a hospitalisation and those who did not, so we doubt that this could constrain our conclusions. Finally, our study has only two time-points, which prevents us from analysing trajectories of decline in exercise capacity.

\section{Conclusion}

This study shows that hospitalisations, particularly if frequent, are significantly related to a greater annual decline in exercise capacity in COPD patients.

\section{Acknowledgements}

The authors' affiliations are as follows. M.A. Ramon: Dept of Pneumology, Hospital Universitari Vall d'Hebron, Barcelona; Departament de Medicina, Universitat Autònoma de Barcelona, Barcelona; and CIBER de Enfermedades Respiratorias (CIBERES), Bunyola, Spain. E. Gimeno-Santos: Centre for Research in Environmental Epidemiology (CREAL), Barcelona; and CIBER Epidemiología y Salud Pública (CIBERESP), Barcelona, Spain. J. Ferrer: Dept of Pneumology, Hospital Universitari Vall d'Hebron; Departament de Medicina, Universitat Autònoma de Barcelona, Barcelona; and CIBERES, Bunyola, Spain. E. Balcells: CIBERES, Bunyola; IMIM (Hospital del Mar Medical Research Institute), Barcelona; Universitat Pompeu Fabra, Departament de Ciències Experimentals i de la Salut, Barcelona; and Dept of Pneumology, Hospital del Mar, Barcelona, Spain. E. Rodríguez: Dept of Pneumology, Hospital Universitari Vall d'Hebron, Barcelona; Departament de Medicina, Universitat Autònoma de Barcelona, Barcelona; and CIBERES, Bunyola, Spain. J. de Batlle: CREAL, Barcelona, Spain; and Section of Nutrition and Metabolism, International Agency for Research on Cancer, Lyon, France. F.P. Gómez: CIBERES, Bunyola; and Servei de Pneumologia (Thorax Institute), Hospital Clínic, Institut d'Investigacions Biomèdiques August Pi i Sunyer (IDIBAPS), Universitat de Barcelona, Barcelona, Spain. J. Sauleda: Dept of Pneumology, Hospital Universitari Son Espases, Palma de Mallorca, Spain. A. Ferrer: CIBERES, Bunyola; IMIM, Barcelona; Universitat Pompeu Fabra, Departament de Ciències Experimentals i de la Salut, Barcelona; Dept of Pneumology, Hospital del Mar, Barcelona; and Dept of Pneumology, Hospital de Sabadell, Corporació Parc Taulí, Sabadell, Spain. J.A. Barberà: CIBERES, Bunyola; and Servei de Pneumologia (Thorax Institute), Hospital Clínic, IDIBAPS, Universitat de Barcelona, Barcelona, Spain. A. Agustí: CIBERES, Bunyola; Servei de Pneumologia (Thorax Institute), Hospital Clínic, IDIBAPS, Universitat de Barcelona, Barcelona; and Fundació Investigació Sanitaria Illes Balears (FISIB), Palma de Mallorca, 
Spain. J. Gea: CIBERES, Bunyola; IMIM, Barcelona; Universitat Pompeu Fabra, Departament de Ciències Experimentals i de la Salut, Barcelona; and Dept of Pneumology, Hospital del Mar, Barcelona, Spain. R. Rodriguez-Roisin: CIBERES, Bunyola; and Servei de Pneumologia (Thorax Institute), Hospital Clínic, IDIBAPS, Universitat de Barcelona, Barcelona, Spain. J.M. Antó: CREAL, Barcelona; CIBERESP, Barcelona; IMIM, Barcelona; and Universitat Pompeu Fabra, Departament de Ciències Experimentals i de la Salut, Barcelona, Spain. J. Garcia-Aymerich: CREAL, Barcelona; CIBERESP, Barcelona; and Universitat Pompeu Fabra, Departament de Ciències Experimentals i de la Salut, Barcelona, Spain.

The members of the PAC-COPD Study Group are: J.M. Antó (principal investigator), J. Garcia-Aymerich (project coordinator), M. Benet, J. de Batlle, I. Serra, D. Donaire-Gonzalez and S. Guerra (all Centre for Research in Environmental Epidemiology (CREAL), Barcelona, Spain); J. Gea (centre coordinator), E. Balcells, À. Gayete, M. OrozcoLevi and I. Vollmer (all Hospital del Mar-IMIM, Barcelona, Spain); J.A. Barberà (centre coordinator), F.P. Gómez, C. Paré, J. Roca, R. Rodriguez-Roisin, À. Agustí, X. Freixa, D.A. Rodriguez, E. Gimeno-Santos and K. Portillo (all Hospital Clínic, Institute d'Investigacions Biomèdiques August Pi i Sunyer (IDIBAPS), Barcelona, Spain); J. Ferrer (centre coordinator), J. Andreu, E. Pallissa and E. Rodríguez (all Hospital General Universitari Vall D’Hebron, Barcelona, Spain); P. Casan (centre coordinator), R. Güell and A. Giménez (all Hospital de la Santa Creu i Sant Pau, Barcelona, Spain); E. Monsó (centre coordinator), A. Marín and J. Morera (all Hospital Universitari Germans Trias i Pujol, Badalona, Spain); E. Farrero (centre coordinator) and J. Escarrabill (both Hospital Universitari de Bellvitge, Institut d'Investigació Biomèdica de Bellvitge (IDIBELL), L'Hospitalet de Llobregat, Spain); A. Ferrer (centre coordinator; Hospital de Sabadell, Corporació Parc Taulí, Institut Universitari Parc Taulí (Universitat Autònoma de Barcelona), Sabadell, Spain); J. Sauleda (centre coordinator) and B. Togores (both Hospital Universitari Son Dureta, Palma de Mallorca, Spain); J.B. Gáldiz (centre coordinator) and L. López (both Hospital Universitario de Cruces, UPV, Barakaldo, Spain); and J. Belda (Instituto Nacional de Silicosis, Oviedo, Spain).

The authors wish to thank the Conjunto Mínimo Básico de Datos de Altas Hospitalarias (CMBDAH) from Catalonia, the Basque Country and the Balearic Islands (all Spain) for providing the information on hospitalisation data.

\section{References}

1 Vestbo J, Hurd SS, Agusti AG, et al. Global strategy for the diagnosis, management, and prevention of chronic obstructive pulmonary disease: GOLD executive summary. Am J Respir Crit Care Med 2013; 187: 347-365.

Barnes PJ, Celli BR. Systemic manifestations and comorbidities of COPD. Eur Respir J 2009; 33: 1165-1185.

Pitta F, Troosters T, Spruit MA, et al. Characteristics of physical activities in daily life in chronic obstructive pulmonary disease. Am J Respir Crit Care Med 2005; 171: 972-977.

4 Kessler R, Faller M, Fourgaut G, et al. Predictive factors of hospitalization for acute exacerbation in a series of 64 patients with chronic obstructive pulmonary disease. Am J Respir Crit Care Med 1999; 159: 158-164.

Oga T, Nishimura K, Tsukino M, et al. Analysis of the factors related to mortality in chronic obstructive pulmonary disease: role of exercise capacity and health status. Am J Respir Crit Care Med 2003; 167: 544-549.

6 ATS Committee on Proficiency Standards for Clinical Pulmonary Function Laboratories. ATS statement: guidelines for the six-minute walk test. Am J Respir Crit Care Med 2002; 166: 111-117.

7 Spruit MA, Polkey MI, Celli B, et al. Predicting outcomes from 6-minute walk distance in chronic obstructive pulmonary disease. J Am Med Dir Assoc 2012; 13: 291-297.

8 Pinto-Plata VM, Cote $\mathrm{C}$, Cabral H, et al. The 6-min walk distance: change over time and value as a predictor of survival in severe COPD. Eur Respir J 2004; 23: 28-33.

9 Oga $\mathrm{T}$, Nishimura K, Tsukino $\mathrm{M}$, et al. Exercise capacity deterioration in patients with COPD: longitudinal evaluation over 5 years. Chest 2005; 128: 62-69.

10 Miravitlles M, Ferrer M, Pont A, et al. Effect of exacerbations on quality of life in patients with chronic obstructive pulmonary disease: a 2 year follow up study. Thorax 2004; 59: 387-395.

11 Garcia-Aymerich J, Serra PI, Mannino DM, et al. Lung function impairment, COPD hospitalisations and subsequent mortality. Thorax 2011; 66: 585-590.

12 Spruit MA, Gosselink R, Troosters T, et al. Muscle force during an acute exacerbation in hospitalised patients with COPD and its relationship with CXCL8 and IGF-I. Thorax 2003; 58: 752-756.

13 Brower RG. Consequences of bed rest. Crit Care Med 2009; 37: S422-S428.

14 Pitta F, Troosters T, Probst VS, et al. Physical activity and hospitalization for exacerbation of COPD. Chest 2006; 129: 536-544.

15 Puhan MA, Gimeno-Santos E, Scharplatz M, et al. Pulmonary rehabilitation following exacerbations of chronic obstructive pulmonary disease. Cochrane Database Syst Rev 2011; 10: CD005305.

16 Garcia-Aymerich J, Gomez FP, Anto JM. Phenotypic characterization and course of chronic obstructive pulmonary disease in the PAC-COPD Study: design and methods. Arch Bronconeumol 2009; 45: 4-11.

17 Garcia-Aymerich J, Gomez FP, Benet M, et al. Identification and prospective validation of clinically relevant chronic obstructive pulmonary disease (COPD) subtypes. Thorax 2011; 66: 430-437.

18 Celli BR, MacNee W, ATS/ERS Task Force. Standards for the diagnosis and treatment of patients with COPD: a summary of the ATS/ERS position paper. Eur Respir J 2004; 23: 932-946.

19 Puhan MA, Mador MJ, Held U, et al. Interpretation of treatment changes in 6-minute walk distance in patients with COPD. Eur Respir J 2008; 32: 637-643.

20 Polkey MI, Spruit MA, Edwards LD, et al. Six-minute-walk test in chronic obstructive pulmonary disease: minimal clinically important difference for death or hospitalization. Am J Respir Crit Care Med 2013; 187: 382-386.

21 Donders AR, van der Heijden GJ, Stijnen T, et al. A gentle introduction to imputation of missing values. J Clin Epidemiol 2006; 59: 1087-1091.

22 Puhan MA, Chandra D, Mosenifar Z, et al. The minimal important difference of exercise tests in severe COPD. Eur Respir J 2011; 37: 784-790.

$23 \mathrm{Bu}$ XN, Yang T, Thompson MA, et al. Changes in the BODE index, exacerbation duration and hospitalisation in a cohort of COPD patients. Singapore Med J 2011; 52: 894-900.

24 Celli BR, Barnes PJ. Exacerbations of chronic obstructive pulmonary disease. Eur Respir J 2007; 29: 1224-1238.

25 Lucas AR, Korol R, Pepine CJ. Inflammation in atherosclerosis: some thoughts about acute coronary syndromes. Circulation 2006; 113: e728-e732. 

obstruction. Am J Respir Crit Care Med 1994; 150: 11-16.

27 Bestall JC, Paul EA, Garrod R, et al. Usefulness of the Medical Research Council (MRC) dyspnoea scale as a measure of disability in patients with chronic obstructive pulmonary disease. Thorax 1999; 54: 581-586.

28 Nishimura K, Izumi T, Tsukino M, et al. Dyspnea is a better predictor of 5-year survival than airway obstruction in patients with COPD. Chest 2002; 121: 1434-1440.

29 Goldstein RS, Hill K, Brooks D, et al. Pulmonary rehabilitation: a review of the recent literature. Chest 2012; 142: $738-749$.

30 Vestbo J, Edwards LD, Scanlon PD, et al. Changes in forced expiratory volume in 1 second over time in COPD. N Engl J Med 2011; 365: 1184-1192.

31 Laupacis A, Wells G, Richardson WS, et al. Users' guides to the medical literature. V. How to use an article about prognosis. Evidence-Based Medicine Working Group. JAMA 1994; 272: 234-237.

32 Gosselink R, Troosters T, Decramer M. Peripheral muscle weakness contributes to exercise limitation in COPD. Am J Respir Crit Care Med 1996; 153: 976-980. 